\title{
Possibilities of benchmarking application in public passenger transport enterprises
}

\author{
J. Gnap \& M. Mikusova \\ Faculty of Operation and Economics of Transport and Communications, \\ University of Zilina, Slovakia
}

\begin{abstract}
The paper describes benchmarking - a systematic approach that provides performance assessment and identification of best practice - as a powerful tool for the development of performance, quality and economic efficiency of transport services. It presents results obtained from the study of pilot benchmarking application in urban public transport enterprises in Slovakia. Based on indicators elaborated in different EU projects, a new method of benchmarking applicable in the area of transport services was designed as well as a set of benchmarking indicators, which enabled the implementation of a comparative study. The proposed method, based on relative best practices, provided for each operator an indication of the remaining potential for performance improvement. The final part of this paper contains recommendations for the creation of a benchmarking system applicable in the field of public passenger transport and gives suggestions for the possible innovation of the presented methodology.

Keywords: benchmarking, urban public transport, quality, evaluation.
\end{abstract}

\section{Introduction}

Public passenger transport represents itself as an important social-economic factor of the surroundings where it operates. It represents services for the population where the main task consists of satisfying their everyday requirements for transportation (travelling to work, schools, offices, medical institutions, etc.). On the one hand, it means that the state tries to support its use and so reduce individual car transport utilization because of ecological, spatial and social reasons. On the other hand, transport companies bound by several 
duties (e.g. the duty of transport operation even though buses are not fully loaded in order to provide transport service within a local area for the public and the duty of providing social discounts for selected groups of citizens) which are limiting them. These companies are loss-making despite providing financial sources as compensation of provable loss resulting from agreement on providing performance within the public interest. State measures are, in most cases, insufficient. Therefore, it is necessary that transport companies themselves struggled for increase of customer number to cover their expenses as well as reach adequate profit. This is closely connected with the need to change from production-oriented management to customer-oriented management.

According to different sources [1-3], in actuality the most important customer request in public transport is the quality of service. It is necessary that transport operators focus their attention on its systematic and continual increase. For this purpose there exist several methods. One of them is benchmarking, which was first used in the 70s by American and Japanese concerns as an important tool for building a quality management system. European companies did not appreciate this principle during that time and "discovered it" significantly later, which could be one of the main reasons for their being behind in terms of productivity and competition; especially behind the U.S.A. Since 1996, benchmarking has therefore been regarded as one of the most influential concepts for acceleration of increase of productivity and competition within globalizing markets of EU member countries.

\section{Concept of benchmarking}

Benchmarking is a tool which enables an increase of quality and effectivity of subjects where applied [4]. It is a method which shows specific practices and processes leading to high performance and at the same time it helps in better understanding how these practices and processes work, leading to the their adaptation and application.

Using benchmarking as the initial point "tutoring organisation" helps contact to be kept with the best ones instead of relying on out-of-date ideas or utopias [5]. Analysis may be focused on company, process or product. Using benchmarking, a company obtains information for improvement and development of what may and should lead to performance improvement.

Benchmarking is not only a process of creation, classification and comparison of collected data but it is, principally, a dynamic process of information exchange, which may be an effective catalyst for change [6]. According to Torok et al. [7], the main contribution of benchmarking to the quality and effectiveness development in a company can be derived from the fact that:

- it encourages and authorizes change management through the implementation of innovations and procedures to reach the best performance;

- it affects an increase of customer and staff satisfaction as well as an increase of company competitiveness; 
- from a long-term perspective, benchmarking may be extremely important for the determination of strategic goals and identification of programs to reach them;

- it increases the consciousness of an organisation's activities and the way they are performed while it requests a significant level of self-evaluation and motivation.

\section{Benchmarking of transport organizations}

The basis for successful benchmarking of transport operators is the existence of a methodology suitable for the conditions within the country where the application of this method will be carried out. This is closely connected with the creation of a set of suitable indicators which enable benchmarking study realization.

\subsection{Creation of benchmarking indicators}

A first step in the process of the creation of benchmarking indicators is the realization of an overview of available sources. Currently, a number of studies and projects exist which deal with benchmarking indicators for the area of transport and their application in practice. The most significant ones at a European level can be highlighted: ISOTOPE (Improved Structure and Organisation for Transport Operations of Passengers in Europe), QUATTRO (Quality Approach in Tendering Urban Transport Operations, Citizens' Network Benchmarking Initiative, BEST (Benchmarking European Sustainable Transport), EQUIP (Extending the Quality of Public Transport), BOB (Benchmarking of Benchmarking), UTBI (The Urban Transport Benchmarking Initiative) and BEST2005 (Benchmarking in European Service of Public Transport).

Apart from the projects mentioned, two standards should also be considered that are dealing with quality topics in the area of public transport - European standard EN 13816 and European standard EN 15140. These standards are focused on quality enhancement within public passenger transport from the user's point of view.

During the process of selection and redesign of benchmarking indicators, it is convenient to respect the following criteria that, according to Alonso et al. [8], can be considered as the most important and basic ones:

- Accessibility;

- Understand ability;

- Reliability;

- Simplicity of data collecting;

- Duplicity exclusion;

- Expenses on data collecting.

Benchmarking indicators mostly consist of a combination of two or more variables. With more detailed investigation in many cases, it is possible to find that it is difficult and, in some cases, even not possible to compare these 
variables (the reason could be e.g. variability of data recording in transport companies that is a derivate from the use of different measuring systems). Indicators created by such variables do not have adequate predicative ability within the local conditions and, for this reason, are not suitable for benchmarking. In order to preserve the above mentioned criteria, it is appropriate to reformulate these indicators in such a way that they would consist only of variables that are regularly and identically measured, documented and processed by the operators (e.g. in the form of a report on service operability and economic results, by fulfilling a transport performance plan, a selected indicator plan and annual development of offered transport capacity, etc.).

After determination of benchmarking indicators, the process continues with finding its joint dependence by the calculation of a correlation coefficient which enables determination of the relationship between two variables and identifies the cohesion of their development. In continuity on dependence determination, indicators are classified by thematic connection into areas. It is also suitable to examine the correlation among indicators connected with the satisfaction of customers and employees; such values being determined by the results of a questionnaire or by observation of the terrain.

The result of the mentioned process is the formulation of a final set of benchmarking indicators determined for performance measurement of transport companies. It is convenient to process them into a unified format e.g. in the form of tables. For each indicator, there should be provided: numerical denomination, name and accurate indicator definition; instructions for the determination of its correct value (formula for calculation and reference on frequent elements and system definitions), the recommended period and method for measurement as well as elements of indicator values distinguished by colour (elements inserted by operator, frequent elements, partial values and final values). Every table also includes a commentary which reminds factors affecting reached values, refers to other connecting indicators and recommends areas for the realization of more detailed benchmarking.

\subsection{Proposal of benchmarking methodology for the area of public passenger transport}

Based on the results of a pilot benchmarking study developed in cooperation with several Slovak urban transport companies, it is possible to divide the process of benchmarking realization into several phases and steps which are illustrated in figure 1 and described in the text below.

\section{1st phase: planning and data collection}

The first step of the benchmarking process is to select and define the critical success factors of an enterprise. These are the elements that the enterprise needs to develop, lead and manage, if it wants to succeed in the market. The competitive position of the enterprise can be improved with the help of knowledge of the market characteristics and the use of the market. The mentioned factors are not clearly defined for the transport sector. But 
the majority of benchmarking indicators can be added to one of the following areas: cost and tariff policy of an enterprise, maintenance of the technical equipment and a fleet, human resources management, and customer orientation of an enterprise.

The second step in the process is the establishment of indicators that are used for measuring the critical success factors. Most of the indicators established under foreign projects were not applicable in the original form. It was necessary to make a selection and transform them. The existence of indicators assigned to the critical success factors greatly simplify the implementation of benchmarking.

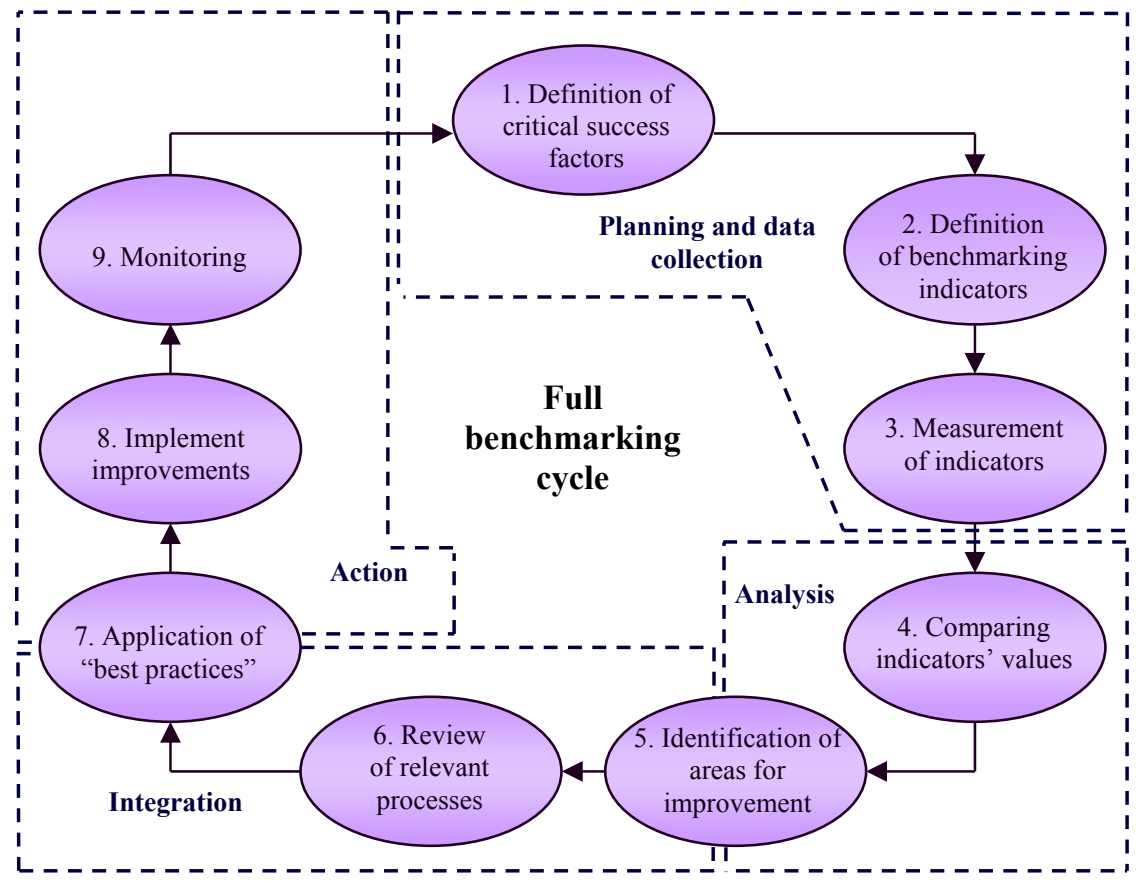

Figure 1: Process of continuous improvement by the application of benchmarking.

The third step is to measure the indicator values. It is necessary to meet the following conditions to ensure comparability of data:

- to understand the content of the indicator;

- to understand the content of relevant components of the indicator;

- to comply with the determined time period of measurement;

- to comply with the determined measurement methodology.

To meet the first two conditions, it is necessary to understand exactly the definition of the indicator itself and also the definition of its sub-components. If one sub-component is not clear, it is recommended to go to the next 
indicator. Incorrect filling of values might impair the steps of the process and it may to lead to a waste of human and financial resources of the stakeholders.

If it is not possible to meet the required time period or the method of measurement for any reason, it is necessary to draw attention to that fact and mention it. It may serve to explain unusual differences in the final values of benchmarking indicators. In the case that an enterprise has only aggregated data of the indicator, it is necessary to apply the same procedure.

After filling in the indicators' file, the file should be sent to a centralized database where it is subjected to further processing. The output should be two clear tables of values whose rows are identified by a numerical code of individual enterprises and columns by numbers of indicators. The second phase of the process starts after obtaining the results from the database.

\section{2nd phase: analysis}

The fourth step of the benchmarking process is to compare the indicator values that were measured in the enterprise with the values of the other participants and to determine significant deviations from the "best in the business" (with determination of a deviation and its threshold value that is acceptable, an enterprise sets itself). For the indicators with positive polarization, the operator is focused on the highest value achieved. For the indicators with negative polarization, the operator is focused on the lowest values.

The selected indicators should be subjected to a detailed examination which is based on the assessment of their linkages with other indicators. The knowledge of partial values of the indicators of the potential benchmarking partner has significant importance for this activity.

Based on the findings, potential areas for improvement are identified, i.e. the areas determined for further in-depth examination through interviews with benchmarking partners. This represents the fifth step of the process, which is also the transition to the next phase of benchmarking.

\section{3rd phase: integration}

The identified differences in the values constitute the basis for determining areas in which the enterprise has reserves or the areas for improvement on which attention should be focused.

The recommendation is to focus not only on one of them for every benchmarking cycle so it is thus necessary to arrange them according to urgency but to pick the area that has the highest priority.

The identified differences in the values constitute the basis for determining areas in which the enterprise has major possibilities for improvement on which attention should be focused. In the initial implementation of the benchmarking, it is highly likely that there will only be a few of these areas. The recommendation is to focus on only one of them for every benchmarking cycle so it is thus necessary to arrange them according to urgency and to pick the area that has the highest priority. 
After selection, there is the sixth step, which consists of the analysis of the relevant business processes. It is necessary to describe in detail all the components of the processes of the identified area and to assess them in a broader context, i.e., in terms of the factors which affect the quality of their output.

It is appropriate to use some of the tools and methods for the identification of problems, which are, for example, pareto analysis, process diagrams, causeand-effect diagrams, etc. All findings from this step should be documented in detail because all future work with benchmarking partners will be based on them.

Then, it is possible to conclude a benchmarking partnership which is a prerequisite to the seventh step of a benchmarking process. Contacting the enterprises should be done with the help of a central database administrator. In the case of a dual match in choosing the benchmarking partner, the partner should automatically provide contact information to the benchmarking enterprises (up to this phase, operators have used the code numbers; no names) and also the partial values of the indicators.

In the case of unilateral interest, the administrator should inform the second party about the possibility of establishing a partnership. Its rejection is possible without any justification, given the fact that the benchmarking principle is providing benefits to both parties involved.

The conclusion of a benchmarking partnership lies in the signing of a contract for the use of confidential data. Another activity of partners is based on the exchange of information about the way to success in the areas that are the subject of the benchmarking. Then, it is necessary to adapt the practice to the specific conditions of the enterprise and the specifics of the environment where the service is provided.

\section{4th phase: action}

Next, the eighth step is to plan and implement the improvements. An operator has to set goals which are achievable, clearly defined, measurable, and timelimited. All employees should be familiar with these goals. Also, it is necessary to determine the means for achieving the goals. These means should be grouped to particular alternatives related to the nature of baseline information on future development.

After the implementation of the measures to improve the current situation, it is appropriate to monitor and analyse the situation in a given area at regular intervals. Based on the findings of differences between plans and reality, it is necessary to correct individual activities which have contributed to achievement of that state. Activity with this concept constitutes the ninth step of the benchmarking process.

It is very important to note that improving enterprise activities is a continuous process. Enterprises should be aware that "nothing is never done so well that it could not be possible to achieve further improvements". That is the reason why benchmarking is a cyclic process. The implementation of the process should 
continue focusing on further areas of improvement and cooperation with new benchmarking partners.

\section{Conclusions}

The benchmarking activities carried out in the area of Slovak urban public transport can be qualified as an examination of the conditions for application of the proposed method and as a preparation of documents for the implementation of the pilot benchmarking project. Methodology adjustment which is presented in this paper within the case study demonstrated its viability and confirmed the potential that benchmarking conceals in itself. The main benefit of the presented and documented approach is that the implementation of this method, in its simple form, does not require large investments and acquirement of the indicators in most cases is not demanding in terms of time, human resources or operational costs. In the study, where the values of two operators from among the organisation of urban public transport in Slovakia were compared, it is possible to express laboriousness and difficulty of obtaining data from the operators' perspective in several hours of work.

The benefits that were positively evaluated by the participating operators were mainly that the methodology applied:

- allows for the gathering and presenting of intercompany data for mutual comparison;

- covers a wide range of business processes;

- evaluates the business processes and their interrelations by using defined indicators;

- is focused ultimately on cost reduction by considering the best experience and it allows for mistakes and errors to be avoided;

- helps to improve the service quality and customer satisfaction, which should be the main objective of those operating urban public transport.

To innovate the benefits of benchmarking, it would be appropriate to extend the set of indicators specific for the area of operators, to assign the weights of importance for individual indicators, and analyse in detail the relationships between indicators. It would also be necessary to include the results of the regular satisfactory survey of passengers and employees into the benchmarking indicators, further to revise or supplement the criteria for selecting a benchmarking partner, and assign business processes, which have a direct impact on the obtained values of the indicators. All these innovations could become the basis for increasing the efficiency and attractiveness of the benchmarking process that can clearly contribute to quality improvement of services provided by public passenger transport operators.

\section{Acknowledgement}

This paper is prepared with the support of the project "The quality of education and development of human resources as pillars of the knowledge society at the 
Faculty PEDAS University of Žilina”, ITMS project code 26110230083, University of Žilina.

\section{References}

[1] Čorejová, T., Rostášová, M., Chrenková, A., Dynamika znalostí a inovačné procesy v sektore Dopravy a logistiky v Žilinskom regióne. Regionálne dimenzie znalostnej ekonomiky, Bratislava: EKONÓM, pp. 267-292, 2011.

[2] Krystek, R., Żukowska, J., Michalski, L., ZEUS Concept and Its Wider European Application. Proc. of Transport Systems Telematics - 10th Conference, TST 2010, Volume 104, pp. 384-390, 2010.

[3] Jankowska, D., Wackowska-Slezak, J., Zukowska, J., Foreign visitors from Visegrad countries with regard to road safety in Poland. Periodica PolytechnicaTransport Engineering, 42 (1), pp. 77-83, 2014.

[4] Soviar, J., Zavodska, A., Knowledge and its creation - the case of introducing product to the market. Verslas: teorija ir praktika $=$ Business: theory and practice, 12 (4), pp. 362-367, 2011.

[5] Mikusova, M., Value of networking in transport policy related to the road safety, Modern transport telematics, Jerzy Mikulski (Ed.) $11^{\text {th }}$ International Conference on Transport Systems Telematics, TST 2011, Katowice-Ustron, Poland, October 2011, Selected Papers, Germany: Springer-Verlag, pp. 7077, 2011.

[6] Montoro, L., Alonso, F., Esteban, C., Toledo, F., Manual de seguridad vial: El factor humano, Ariel-Planeta, 2000.

[7] Torok, A., Junevičius, R., Meszaros, F., Economic and social modelling of urban traffic controlling. Proc. of the 13th IFAC Symposium on Control in Transportation Systems, CTS 2012, Sofia, Bulgaria, pp. 292-296, 2012.

[8] Alonso, F., Montoro, L., Torosa, F., Martinez, T., "Estado del arte" de la psicología aplicada al tráfico y la seguridad vial. Anuario de Psicología, 65, pp. 29-44, 1995. 